\title{
LANGUAGE SHIFT IN NEWAR: A CASE STUDY IN THE KATHMANDU VALLEY
}

\section{Bhim Lal Gautam}

This paper explores the patterns of language shift in Newar, the ethnic indigenous language community living in the Kathmandu Valley. The research focuses on language contact situations in different domains viz. social, cultural, personal, and official as well as media related activities where the informants are asked to use different languages along with the use of their own mother tongue i.e. Newar. This socio-ethnographic research aims at providing some clues as to how the discovery of a minority language triggers changes in representations and attitudes.

Keywords: language shift, causes and impacts, ideology, globalization

\section{Introduction}

The Newars are commonly believed to be the indigenous inhabitants of the Kathmandu Valley, and are recognized as such in the historical descriptions of the Nepal Valley (Malla 2015). The civilization and culture of the Kathmandu Valley are identified with the Newar civilization and culture. Nepali (1965) has observed that "the Newars are a people with a high degree of material culture and a distinctive social organization. "The origin of the Newars, however, still remains uncertain and the proto identity of the Newar people continues to be disputed among various schools of thought. Grierson (1909) in the Linguistic Survey of India had proposed the popular hypothesis that there were two branches of migration along the Himalayas from east to west, while Chatterjee (1950) and Regmi (1960) assign the first branch to North Assam (the Newars included) and the second branch to Outer Mongolia and Tibet in the north. Scholars thus have not been able to connect the Newars with the migration pattern proposed in the Linguistic Survey of India.

The Newar speakers are concentrated in the three major cities of the Kathmandu Valley viz. Kathmandu, Lalitpur and Bhaktapur and welldefined range of urban settlements across the country. The CBS Census Report of 2001 gives a total of $12,45,232(5.4 \%)$ ethnic Newars, and $8,25,458(3.03 \%)$ mother-tongue speakers which indicate a decline of $33.7 \%$ inactive speakers.
Census 2011 reports there are 13,21,933 ethnic Newars and 846557 (3.2\%) mother tongue speakers. Some view this trend as alarming, but the Newars continue to use their language extensively in many domains of socio-cultural contexts, trade and commerce, education, literature and massmedia. The Newars are also a highly literate community.

Newar also known as Nepal Bhasa, is a SinoTibetan language spoken by the Newar people, the indigenous inhabitants of Nepal Mandala, which consists of the the Kathmandu Valley and surrounding regions in Nepal. Although "Nepal Bhasa" literally means "Nepalese language", the language is not the same as Nepali, the country's current official language. The two languages belong to different language families (SinoTibetan and Indo-European respectively), but centuries of contact have resulted in a significant body of shared vocabulary. Both languages have official status in Kathmandu Metropolitan City. Newar was Nepal's administrative language from the 14th to the late 18th century. From the early 20th century until democratization, Newar suffered from official suppression. From 1952 to 1991, the percentage of Newar speakers in the Kathmandu Valley dropped from $75 \%$ to $44 \%$, and today Newar culture and language are under threat. The language has been listed as being "definitely endangered" by UNESCO. The typological and genetic classification of Newar/Nepal Bhasa has been controversial for several reasons. However, contributing factor has to do with the long period of contact with Sanskrit, Prakrit and other Indic languages resulting in considerable lexical and grammatical borrowings.

Although Newar population has increased between the 1952/54 to 2011 censuses, the Newar group no longer maintains numerically the highest position in Kathmandu district in the 2011 census. It is simply because a large number of Hill Brahman and other ethnic groups migrated into the Kathmandu Valley recently because of the Maoist insurgency in Nepal from 1996 to 2006 for 
34 / Language ...

reasons of security and employment.

Table 1: Newar mother tongue population in different census

\begin{tabular}{|l|l|l|l|}
\hline SN & Census Year & $\begin{array}{l}\text { Total } \\
\text { Population }\end{array}$ & $\begin{array}{l}\text { Percentage in } \\
\text { Total population }\end{array}$ \\
\hline 1 & $1952 / 54$ & 383184 & $4.65 \%$ \\
\hline 2 & 1961 & 377721 & $4.01 \%$ \\
\hline 3 & 1971 & 454979 & $3.94 \%$ \\
\hline 4 & 1981 & 448746 & $2.99 \%$ \\
\hline 5 & 1991 & 690007 & $3.73 \%$ \\
\hline 6 & 2001 & 825458 & $3.63 \%$ \\
\hline 7 & 2011 & 846557 & $3.20 \%$ \\
\hline
\end{tabular}

In addition, every year a lot of people migrate to the Kathmandu valley searching for jobs, education, business etc. and eventually settle in the valley.

Table 2: Newar population in two censuses

\begin{tabular}{|c|c|c|c|c|c|c|c|}
\hline \multirow{2}{*}{$\begin{array}{l}\mathrm{S} \\
\mathrm{N}\end{array}$} & \multirow{2}{*}{$\begin{array}{l}\text { District } \\
\mathrm{s}\end{array}$} & \multicolumn{3}{|l|}{2001} & \multicolumn{3}{|l|}{2011} \\
\hline & & $\stackrel{\pi}{0}$ & $\sum_{0}^{\pi}$ & 责 & 营 & $\sum^{\pi}$ & 폴 \\
\hline \multirow[t]{2}{*}{1} & Kathm & 295 & 146 & 149 & 383 & 190 & 192 \\
\hline & andu & 439 & 279 & 160 & 136 & 297 & 839 \\
\hline \multirow[t]{2}{*}{2} & Lalitpu & 138 & 683 & 705 & 155 & 767 & 789 \\
\hline & $\mathrm{r}$ & 938 & 86 & 52 & 604 & 03 & 01 \\
\hline \multirow[t]{2}{*}{3} & Bhakat & 126 & 630 & 634 & 138 & 692 & 696 \\
\hline & apur & 592 & 98 & 94 & 873 & 39 & 34 \\
\hline \multirow{2}{*}{\multicolumn{2}{|c|}{ Total }} & 560 & 277 & 283 & 677 & 336 & 341 \\
\hline & & 969 & 763 & 206 & 613 & 239 & 374 \\
\hline
\end{tabular}

Table 2 shows that Newar population in the Kathmandu valley is increasing but if we compare the ratio of total population, we can easily guess that it is decreasing day by day because of development, communication and urbanization.

\section{Methodology}

\subsection{Theoretical framework}

This research was mainly based on the data collected through questionnaires which were developed in 2014 by the researcher in DDL, University of Lyon 2, France and their pilot testing was done in 2015 in Kathmandu. The questionnaires were translated into Nepali and administered to the concerned informants. Moreover, this paper is also based on some existing literature related to language contact and language ideologies while describing and analyzing the data. The data were collected and analyzed following the mixed method approaches i.e., quantitative and qualitative.

\subsection{Tools for the study}

a. Survey questionnaires

There were 45 indicators in the questionnaires altogether containing metadata information and questions for language use and attitude. The collected data was analyzed by following the recent developments of language contact, ideology and sociolinguistic studies.

\section{b. Focus group discussions (FGD)}

There were four FGDs in four different research sites in this research. One FGD was conducted for each of the Linguistic/speech communities involved. There were about 5-7 members in each of FGD. Members were purposively selected from sex, age, occupation and education strata.

\section{c. Interview}

At least 8 individual interviews were conducted in order to meet the need and objective of the research focusing on the language attitude and ideology in multilingual context.

\subsection{Selection of informants}

The data was mainly collected from the people of Newar language communities like housewives, teachers / academicians / monks, politicians / language activists, businessmen/shopkeepers, trekking guides / workers/ vendors, students. All the informants were selected on A1, A2 and A3 group classifying into male / female, literate / illiterate whenever possible. A1 belongs to the age between15-30, A2 belongs to 31-55 and A3 belongs to 56 and above. Figure 1 shows the brief information about the informants.

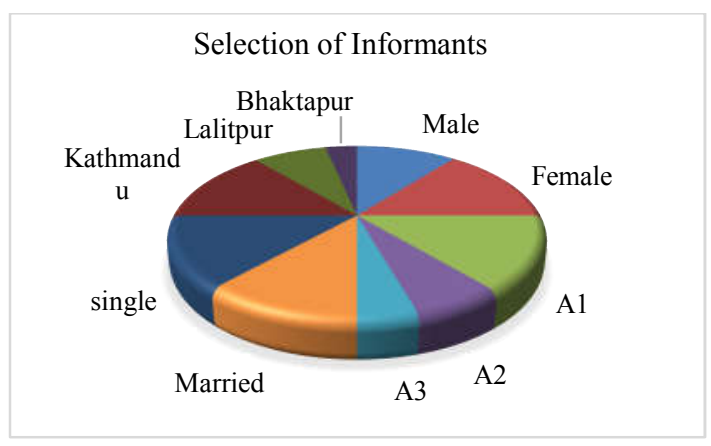

Figure 1: Selection of informants 


\subsection{Data collection}

The primary data was collected with the help of questionnaires and recording FGDs and interviews. Questionnaires were used for language use and attitudes and FGDs and interviews for sociolinguistic analysis of language shift in Newar. The source of data was based on researcher's informal field study like social talking, business talking, debate and conversations etc. rather than written sources. The secondary data were collected from different libraries and sources available.

\section{Patterns of language shift}

This part mainly deals with the trends of language shift focusing on the diverse domains of language use and attitudes among the Newar language speakers living in the Kathmandu Valley. The researcher administered questionnaires containing 45 indicators in different five selected areas of the Kathmandu Valley including some FGDs and informal interviews. The trends and patterns of shift noticed in Newar languages are described below.

\subsection{Informal situations}

In informal situations people do various activities informally without being conscious and caring about the outer community. The informal situations in this speech community comprise two types of activities: behavioural and personal. They are briefly discussed as follows:

\section{a. Behavioural activities}

Behavioural activities in this research refer to the activities that indicate different psychological behaviours of the informants. They include the activities like making friends, different reading and writing activities, making telephone calls, talking with different people, shopping, passing exams and so on.

Table 3 shows that The Nepali language is used highly in almost all the domains in comparison to Newar, English and Hindi. The influence of English is much higher than that of Hindi because of education, globalization and tourism among the Newar speaking community in the Kathmandu Valley. Newar is highly used for making friends, shopping, telephone calls and talking with workers rather than other activities. The use of English is very high for reading/writing, passing exams, getting jobs and talking with teachers and academicians.

Table 3: Patterns of language use in behavioural activities $(\mathrm{N}=45)$

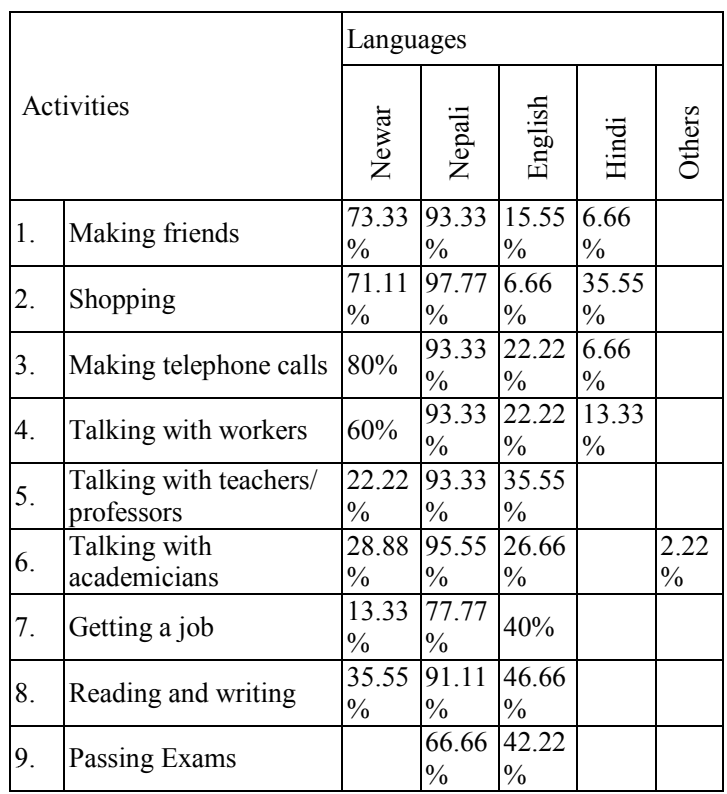

b. Personal activities

Personal activities in this research mean those activities which are connected to the personal and interpersonal activities of the informants. They include activities like joking, singing, praying, bargaining, abusing, telling stories and so on.

\section{Personal Activities}

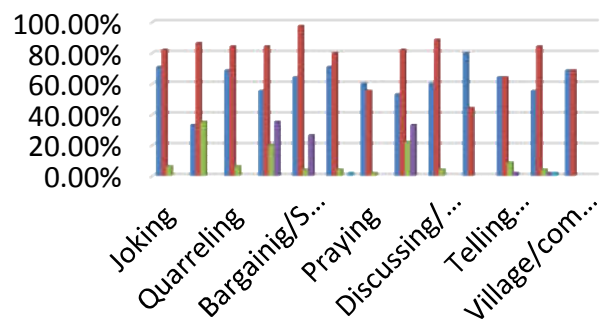

$\square$ Newar $\square$ Nepali $\square$ English $\square$ Hindi $\square$ Others

Figure 2: Language use in personal activities 
36 / Language ...

Figure 2 shows that Newar, Nepali and English are used in most of the activities like joking, singing, praying, bargaining with highest frequency than Hindi and other languages. Here the use of Hindi is very low because of these informal personal activities.

As marked in the Figure 2, the Newar language is dominant among the Newar mother tongue speakers in the activities of joking, quarrelling, verbal abusing, family gathering and village/community meetings or gatherings. However, the Nepali language is more dominant in the activities of singing inside and outside, counting, discussing and shopping/marketing. Presence of Hindi is clearly noticed in the activities of shopping, singing inside and outside. English is used to in most of the activities except family gathering. The figure also demonstrates that in the activities of village/community meeting, telling stories to children and telling stories to others, both Newar and Nepali are found parallel in use.

From the close observation of the figure above and my interview transcripts (FGD/individual) collected from the field, it is apparent that the Nepali language is gradually being dominant among the Newar mother tongue speakers. As a Newar man (56) commented, "We use the Newar language at home and community since we are all Newars here; but when we go to our children's schools, or go to Shahar (Kathmandu city) for shopping, we use Nepali, so I know both languages and need both for different situations." (Interview, February 2018) Though a small segment, the comment of this Newar man indicates how language use is in shifting trend from Newar to Nepali even in the personal activities.

\subsection{Formal situations/activities}

The table 4 below shows the use of language among Newar mother tongue speakers in the formal situations and activities. As the table indicates, Nepali is found highly dominant among the Newar mother tongue speakers in the formal situations and activities. In the activities of reading and writing, seeking jobs, attending exams, talking to teachers and intellectuals, language use in offices and work places as well as social political activities, Nepali is most influential.

Table 4: Patterns of language use in personal activities $(\mathrm{N}=45)$

\begin{tabular}{|c|l|c|c|c|c|c|}
\hline \multicolumn{2}{|c|}{ Situations } & \multicolumn{5}{|c|}{ Languages } \\
\cline { 3 - 7 } \multicolumn{2}{|c|}{} & $\begin{array}{c}\text { New } \\
\text { ar }\end{array}$ & $\begin{array}{c}\text { Nep } \\
\text { ali }\end{array}$ & $\begin{array}{c}\text { Engl } \\
\text { ish }\end{array}$ & $\begin{array}{c}\text { Hin } \\
\text { di }\end{array}$ & $\begin{array}{c}\text { Oth } \\
\text { ers }\end{array}$ \\
\hline 1 & Office/ & 33.3 & 84.4 & 15.5 & 4.44 & \\
& workplace & $3 \%$ & $4 \%$ & $5 \%$ & $\%$ & \\
\hline 2 & Political/ social & 44.4 & 88.8 & 2.22 & & \\
& gathering & $4 \%$ & $8 \%$ & $\%$ & & \\
\hline 3 & Public activities/ & 51.1 & 88.8 & 4.44 & & \\
& fun fair & $1 \%$ & $8 \%$ & $\%$ & & \\
\hline 4 & & 6.66 & 97.7 & 8.88 & & \\
& Administration & $\%$ & $7 \%$ & $\%$ & & \\
\hline 5 & & 8.88 & 97.7 & 4.44 & 2.22 & \\
& Strangers & $\%$ & $7 \%$ & 5 & $\%$ & \\
\hline
\end{tabular}

As commented by many aged literate people of the typical Newar community in Kathmandu, the fundamental reason for the people shifting from Newar to the Nepali language is that it is not a medium of instruction in schools. The table also indicates that the Newar language occupies no space among the native speakers of this language in the administrative works. In some cases, English is found more dominant than the Newar language. The presence of Nepali and English among the Newar speakers in this manner implies the process of shifting from Newar to Nepali and English.

The dominance of the Nepali language among the Newar mother tongue speakers can be observed in the personal stories as well. As a Newar woman (65 years) comments, "Children these days speak either Nepali or English; they use Newar language only when we Newar speaking parents and grandparents talk to them; they do not prefer to speak Newar; they mix up Nepali and English words even if they speak Newar at all" (Interview, February 2018).

\subsection{Religious and cultural activities}

Table 5 demonstrates the trend of language use among newer mother tongue speakers in religious and cultural activities. Presence of Newar and Nepali can be seen in all the activities listed here under the various domains of religious and cultural activities. However, use of the Newar language is dominant in each and every case. Presence of English is very rare in cultural programs, marriage 
ceremony and cultural festivals and the use of Hindi is almost zero in the data.

Table 5: Patterns of language use in personal activities $(\mathrm{N}=45)$

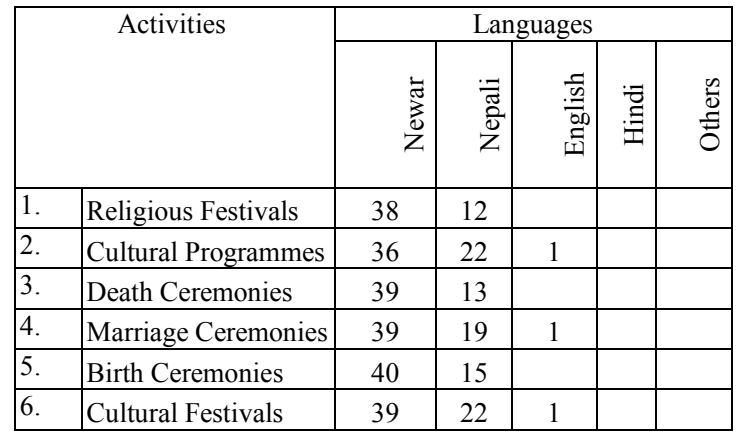

\subsection{Family and friends}

Table 6 demonstrates the language use trends among people speaking Newar as mother tongue while communicating with family members and friends.

Table 6: Patterns of language use in personal activities $(\mathrm{N}=45)$

\begin{tabular}{|c|c|c|c|c|c|}
\hline \multirow[t]{2}{*}{ Persons } & \multicolumn{5}{|l|}{ Languages } \\
\hline & 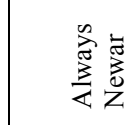 & 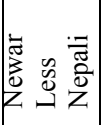 & 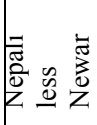 & 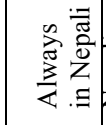 & 醇 \\
\hline Father & $87 \%$ & $8.88 \%$ & & $11.11 \%$ & \\
\hline Mother & $84.44 \%$ & $6.66 \%$ & & $8.88 \%$ & \\
\hline Brother/ Sister & $77.77 \%$ & $2.22 \%$ & $4.44 \%$ & $15.55 \%$ & \\
\hline \begin{tabular}{|l} 
Spouse \\
\end{tabular} & $53.33 \%$ & $2.22 \%$ & & $8.88 \%$ & \\
\hline \begin{tabular}{|l|} 
Friends at home \\
\end{tabular} & $51.11 \%$ & $26.66 \%$ & $2.22 \%$ & $20 \%$ & \\
\hline Friends outside & $15.55 \%$ & $24.44 \%$ & $15.55 \%$ & $31.11 \%$ & $13.33 \%$ \\
\hline $\begin{array}{l}\text { Neighbour at } \\
\text { home }\end{array}$ & $55.55 \%$ & $13.33 \%$ & $8.88 \%$ & $22.22 \%$ & \\
\hline $\begin{array}{l}\text { Neighbours } \\
\text { outside }\end{array}$ & $31.11 \%$ & $26.66 \%$ & $11.11 \%$ & $31.11 \%$ & \\
\hline
\end{tabular}

We see the presence of Nepali and Newar in all domains. While communicating with friends outside home, use of Nepali is more dominant; but Newar is more dominant in the case of communication with friends at home. Talking with the immediate relatives of family (spouse, parents and siblings), Newar is dominant.

\subsection{Media and entertainments}

Table 7 demonstrates the trend of language use among Newar mother tongue speakers in the activities under the domain of media and entertainment.

Table 7: Patterns of language use in personal activities $(\mathrm{N}=45)$

\begin{tabular}{|c|l|c|c|c|c|c|}
\hline \multicolumn{2}{|c|}{ Activities } & \multicolumn{5}{|c|}{ Languages } \\
\cline { 2 - 7 } & $\begin{array}{c}\text { New } \\
\text { ar }\end{array}$ & $\begin{array}{c}\text { Nep } \\
\text { ali }\end{array}$ & $\begin{array}{c}\text { Engli } \\
\text { sh }\end{array}$ & $\begin{array}{c}\text { Hin } \\
\text { di }\end{array}$ & $\begin{array}{c}\text { Othe } \\
\text { rs }\end{array}$ \\
\hline 1 & $\begin{array}{l}\text { Watching Movie/ } \\
\text { Serial }\end{array}$ & 16 & 40 & 15 & 34 & 9 \\
\hline 2 & Watching News & 10 & 44 & 8 & 13 & \\
\hline 3 & Listening Music & 26 & 38 & 17 & 35 & \\
\hline 4 & $\begin{array}{l}\text { Listening } \\
\text { Radio/News }\end{array}$ & 19 & 44 & 11 & 5 & \\
\hline 5 & $\begin{array}{l}\text { Listening } \\
\text { Interview }\end{array}$ & 18 & 44 & 10 & 10 & \\
\hline 6 & $\begin{array}{l}\text { Reading } \\
\text { Newspaper }\end{array}$ & 13 & 41 & 15 & 2 & \\
\hline 7 & $\begin{array}{l}\text { Reading } \\
\text { horoscope }\end{array}$ & 9 & 42 & 15 & 1 & \\
\hline
\end{tabular}

Table 7 shows that Nepali is dominant in media and entertainment activities compared to Newar itself. As the data indicate, Newar mother tongue speakers use the native language in the activities of watching TV serials, TV news and listening to music; however, it is less dominant in these activities. In the activities of listening to news, listening and watching interviews, reading newspapers and reading horoscopes, Nepali retains its wide dominance among the Newar mother tongue speakers. Hindi is found to occupy more space in the activity of watching TV serials and listening to music. English marks presence in media and entertainment activities including watching TV serials and reading newspapers. However, these languages (Hindi and English) are not so wide as Nepali is in media and entertainment activities among the Newar mother tongue speakers.

\section{Language contact and intergenerational shift}

Multilingualism, language contact and language shift are the inherent miracles in Nepal. Language shift, sometimes discussed as language transfer or language replacement or assimilation, is the process whereby a speech community of a language shifts to speak another language, usually over an extended period of time. The language shift may have different effect on language community. There may be cultural shift along 
with language shift; and some different language can emerge. Language shift is one of the effects of globalization. Nepal's labour migration and market force have their effect on language shift. Nepal's labours working in different countries are acquainted with the languages used in those countries. As a result, there is language shift. There may occur communication problem as well among the speakers of the same language if they are of different ages and reside in different places.

Most of the adult people of Newar community interviewed during the fieldwork said that they use Newar language while talking to their older generations, but Nepali while communicating with the younger ones. And, such a shift found among younger generations towards Nepali and even English (to some extent) has been reinforced along with the growing influence of modern media and technology. The generation gap among the different age groups can be found in a remark made by a Newar man (56) who said, "I myself and my wife like Newar TV programs, but my daughter prefers Hindi serials, she always watches these serials, and for son enjoys sports mostly in English language" (Interview, February 2018).

However, in some cases, the younger generation people (15-25 years) were found using the mother tongue in all the personal activities covered by this study. Newar speakers have used their native tongue in the domains of cultural, religious and some of the formal situations as well. However, data indicates that the younger generation of mother tongue speakers are gradually motivated to other 'dominant' languages under the influence of current globalization, education, migration, business and communication, and technologies and the media.

\section{Causes and impact of language shift}

This section explores the causes and impacts of such shifts in languages spoken by Newar people in the Kathmandu Valley. The analysis of FGDs, individual interviews and field observations demonstrate the following causes and impacts.

5.1 Media, migration and marriage (M3)

The analysis of the data demonstrates that there are many causes that promote language contact. Media, migration and marriage (M3) are found to retain some vital impact in contact and shift. Growing consumption of media, no matter whether that be electronic or print, makes the local mother tongue speakers get exposed to regional and global languages. As it is observed in the Nepal's linguistic landscape, the natural influence of Nepali, Hindi and English medium TV channels is apparent. Such influence could be observed in people's growing consumption of Nepali channels especially for news, entertainment and information of the diverse social, cultural and political aspects of the state; Hindi channels especially for entertainment; and English channels in order to get entertainment, sports and international/global exposure. On the other hand the growing use of internet on various social networking sites like Facebook, Twitter, Skype, Viber, etc. have forced people to shift towards English and many other foreign languages through smart phones, pads and computers.

Migration, as pointed out above, is another vital cause of language contact and shift. In the Kathmandu valley, the city of Kathmandu has almost 42 per cent internal migrants from both rural and urban areas of other districts (CBS 2011). The absent population of Nepal has been a major issue in demographic, social and economic aspects of the country. The absent population reported in 2011 was 1,921,494, a big jump from the number of 762,181 of the census of 2001.Nepal currently results widespread internal as well as external migration rates in the history. As my analysis points out, internal migration has provided the space for promoting language shift from local languages to Nepali, English and Hindi languages because of the heavy migration of different people in the Kathmandu valley.

Marriage is another cause for migration that often promotes language shift. Marriage that occurs between the members of inter-lingual background is quite imperative to understand how it promotes language shift. Sony, a Newar speaking woman's experience often demonstrates that how her marriage to a Nepali speaking Tamang man ultimately pushed her to shift from Newar to Nepali. Thus, the data indicate that marriage has become an important cause of language shift 
mostly in the case of female participants of diverse ethnic groups.

\subsection{Education}

The next indicative cause that encourages language shift is education/educational access. The state's ideology to expose the young citizens with more dominant national, regional and international languages promotes the language shift especially on the young citizens. The analysis indicates that Newar explored in this study is extensively used in its respective local contexts. However, the language has not been (well) recognized in formal schooling and academic institutions. Even some practices of educating young children in their mother tongues have been appropriately materialized due to the lack of public interest, concrete policies on mother tongue education, and parental desire to expose their children with more dominant languages such as Nepali and English. Since "English-prioritized schooling access for the children is often perceived as the symbol of better future, better social status and economic soundness of the household" (Devkota, 2018, p. 111), parents are more motivated to make their children to learn English and Nepali languages instead of their mother tongues.

In Newar dominant community of the Kathmandu Valley, many of my participants often explained how their children have been extensively exposed to Nepali and English languages in place of their mother tongues. Badri Lal Maharjan (75 yrs.) from a typical Newar speaking community said, "In the very past, there was the provision of the Newar language subject in school curricula along with Nepali and English, but now schools don't teach that, our children do not study the Newar language anywhere formally, they learn Nepali and even more English instead, so how they could learn the Newar language" (Interview, February, 2018).

In FGDs, that took place in three major areas of the Kathmandu Valley, the participants often explained how their children have been extensively exposed to Nepali and English in place of their mother tongues.

\subsection{Travel and tourism}

Nepal is not only linguistically and culturally diverse, but also ecologically and geographically distinct. Due to its diversity in geography as well as rich and unique climate, Nepal has a wide range of plant and animal species, famous for its flora and fauna, beautiful rivers and lakes. Nepal is the land of world's highest peak, Sagarmatha (Mt. Everest), Lumbini, the birth place of Buddha, Janakpur, birthplace of Janaki and Pashupatinath temple where visitors from across the world visit for different purposes. Every year thousands of people from around the world visit Nepal for many reasons. Some of them are on holiday, while some of them want to study, the languages and cultures of the people and the country's natural resources. For all of these visitors, whatever their national languages, English plays a significant role as a medium of communication, from booking tickets and hotels to arranging travel and trekking during their stay in Nepal.

All stakeholders associated with the travel and tourism industry, such as hotel, restaurant and trekking entrepreneurs, must have knowledge of English in order to communicate with the tourists. Not all people involved in this business are highly educated. Some are illiterate and run small lodges and restaurants on their respective areas. They automatically develop the competence of foreign languages like English, Hindi, Chinese, etc. through the direct contact with foreigners. Thus the travel and tourism is one of the important factors of language contact and shift from local language to many foreign languages. Many Newar people involved in this field understand and speak these languages.

\subsection{Market force and economic benefits}

Market force is another reason that is found intricately connected to the economic benefits of the individuals. This research demonstrates a number of examples from diverse study sites where people are using and shifting their language because of business and economic purpose. A businessman (Ravi,47 yrs.) at Patan said, "I like to speak my own language but I have to speak Nepali, English or Hindi otherwise people do not come to my shop" (Personal Interview, 2018: my translation). The story of Ravi can be understood 
how language shift is guided with the market force particularly business.

Current market force is seen to be imperative in language shift in different ways. Growing trend of external migration of Nepali citizens in the international labour markets encourages them to learn a particular language(s) that benefits them in a particular social context; no matter it is extensively for instrumental purpose in the beginning. It ultimately ensures language shift. Similarly, another Newar speaking man (38) from Bhaktapur commented, "Where are our languages, I mean Newar, Tamang, Gurung....in media we listen to Nepali and English, even Hindi rather than our local languages, we read English, Nepali, Hindi ....in the advertisements and manuals of materials we buy at home... we have to go to other countries for work or study, so what happens if we don't learn these languages?" The participants' comments as such clearly hint why people get motivated to the languages such as Nepali in the national context and English or other dominant languages under the influence of current market force.

\subsection{Political-ideological intervention}

Political-ideological intervention of the state is another powerful cause in promoting language shift through contact. The 1959 and 1962 constitution of Nepal confers the status of the national language to Nepali. During this period, Nepali has taken great advances to raise itself to the status of the national language. Although studies on the comprehension and the use of Nepali by non-Nepali speakers are far and few between completefeasibility seems to have driven more and more non -Nepali speakers to use and understand it in their day to day transactions, inter-ethnic communications and above all in their communication with the channels of the local and national administration. Since the very instigation of modern Nepal, the Nepali language was promoted as the language of unity, the language of social harmony and national integration. As well, the Nepali language was also intensively employed in schooling/education, media and formal communication in the state. Such intervention has ideally promoted the Nepali language throughout the nation.
Due to the lack of a concrete plan by the Nepalese government regarding the development of the ethnic languages, the English language, along with Nepali, has been predominant in school curricula, both in the rural and urban areas of Nepal. The learning of English provides Nepalese with opportunities to obtain jobs in various national and international governmental organizations and in the media. Therefore, a large section of the Nepalese people is attracted to the English language more than other local languages.

As it is explored from the interviews and FGDs, the growing shift to Nepali and English language is because of its extensive use and applicability in the formal situations, media, education and other formal fields in the nation. The narratives of the respondents belonging to diverse the socioeconomic backgrounds demonstrate that their shift to Nepali and English is mostly related to fulfilling the pragmatic purposes.

\section{Summary}

The data presented in this study shows that mother tongue is highly used in cultural and religious activities. Nepali is dominantly used in social, official, ceremonial and media related activities. English and Hindi languages are used in media, ceremonial and official activities. The influence of English is much higher than Hindi among Newar people which indicates the influence of globalization and western traditions. Newars have been directly involved in official and academic activities as well as tourism which motivate them to contact with many foreigners in English and Nepali rather than other languages. A shift in a language often brings about a shift in identity and there may be resistance to adopting a new language. The new language and the new identity may be actively promoted or persuaded. Newars living in the capital city have been influenced directly and indirectly by the globalization and international linkage and communication. Moreover, they have been involved in various social, cultural and ceremonial activities with the new mixed society which motivates them to shift into new target languages from the ancestral source language. In this context, this study is connected with the sociopolitical factors/variables where different 
language communities/speakers share different contexts and situations. So the multilingualism in the Kathmandu Valley has become an obligatory part of people living in this city. Existing political, social and economic factors contribute to language use and attitude. Nepali being the dominant language in the capital city, the lingua franca of the country and English being the international language of various purposes is becoming more valuable and influencing in Newar speaking community warn language shift and endangerment.

\section{References}

Central Bureau of Statistics. 1952/54. Population Census, National Planning Commission (NPC), Kathmandu, Nepal.

Central Bureau of Statistics. 1961. Population Census, National Planning Commission (NPC), Kathmandu, Nepal.

Central Bureau of Statistics. 1971. Population Census, National Planning Commission (NPC), Kathmandu, Nepal.

Central Bureau of Statistics.1981. Population Census, National Planning Commission (NPC), Kathmandu, Nepal.

Central Bureau of Statistics. 1991. Population Census, National Planning Commission (NPC), Kathmandu, Nepal.

Central Bureau of Statistics. 2001. Population Census, National Planning Commission (NPC), Kathmandu, Nepal.

Central Bureau of Statistics .2011. Population Census, National Planning Commission (NPC), Kathmandu, Nepal.

Chatterjee, Suniti K. 1950. Kirata-Jana-Kriti : The Indo-Mongoloids: Their Contributions to theHistory \& Culture of India. Calcutta: The Royal Asiatic Society

Devkota, Kamal Raj. 2018. Navigating exclusionary-inclusion: Experience of dalit school children in rural Nepal. Globe: Journal of Language, Culture and Communication. Vol. 6, pp. 106-120. Alborg: Alborg University Press.

Grierson, George A. 1909. Linguistic Survey of India (vol. 3). Calcutta: Office of the Superitendent of Government Printing, India.
Kansakar, Tej R. 1999 The Newar Language:A Profile.A Journal of Newar studies 1:1,1128,Portland USA

Kansakar, Tej R. 2011 A Sociolinguistic Survey of Newar (Nepal Bhasa) A report submitted to LINSUN,Central Department of Linguistics, TU

Kroskrity,P.V.2004 Language Ideologies.In A. Duranti(Ed.) A companion to linguistic anthrolopology (496-517) Oxford.Blackwell.

Malla,Kamal P. 2015.From Literature to Culture:Selected writings on Nepalese studies, 1980-2010 Kathmandu Social Science Baha.

Nepali, Gopal Singh. 1965. The Newars: An Ethno-Sociological Study of a HimalayanCommunity. Bombay:United Asia Publications.

Regmi, D.R. 1960 /1969. Ancient Nepal.Calcutta: Mukhopadhyaya. Third Edition. 